\title{
Alcoholic Hepatitis
}

National Cancer Institute

\section{Source}

National Cancer Institute. Alcoholic Hepatitis. NCI Thesaurus. Code C34684.

Inflammation of the liver resulting from ingestion of alcohol. 